\title{
Management of acute primary angle-closure glaucoma: a long-term follow-up of the results of peripheral iridectomy used as an initial procedure
}

\author{
T. JUSTIN PLAYFAIR AND PETER G. WATSON \\ From the Department of Ophthalmology, Addenbrooke's Hospital, Cambridge
}

SUMMARY For the past 12 years peripheral iridectomy has been used as the initial surgical procedure after an acute attack of angle-closure glaucoma. The operation has been performed 2 to 5 days after the pressure has been controlled medically and has been followed routinely by prophylactic peripheral iridectomy in the fellow eye. Peripheral iridectomy for primary acute angle-closure glaucoma controlled the condition without any need for further medical or surgical therapy in $72 \%$ of cases. Careful and frequent follow-up within the first 4 postoperative months is essential to prevent further field loss, which can occur very rapidly if the pressure is not adequately controlled. If the pressure remains uncontrolled, further surgery should not be delayed. It was impossible to decide which patients would eventually need trabeculectomy when they first attended in the acute attack. Peripheral iridectomy as a prophylactic procedure was entirely effective in preventing an acute angle-closure attack in the fellow eye.

von Graefe introduced broad iridectomy as an effective operation for acute glaucoma in 1856 (von Graefe, 1857; Adler, 1929 abridged translation). He also found broad iridectomy to be useful in some forms of chronic glaucoma and in neglected cases of acute glaucoma with field loss and optic disc cupping. However, he was uncertain of its mode of action. Curran (1920, 1931) recognised that iridectomy was usually only successful in either congestive or non-congestive glaucomas if the anterior chambers were shallow. He introduced the concept of pupil and angle blockage in angle-closure glaucoma and realised that iridotomy or iridectomy allowed drainage from the posterior to the anterior chamber, thus bypassing the relative pupil blockage. Barkan (1938), following his studies with the gonioscope, clearly separated off primary angleclosure glaucoma from chronic simple glaucoma. A clear exposition of these theories and the surgical management of angle-closure glaucoma was given by Chandler (1952), in which he also described the simple, safe method of peripheral iridectomy now in almost universal use.

The method of peripheral iridectomy introduced by Curran (1920) consisted in puncturing the limbus with a Knappe needle knife and incising the iris

Address for reprints: Mr P. G. Watson, FRCS, 17 Adams Road, Cambridge CB3 9AD above. This technique was much safer and led to many less complications than the von Graefe iridectomy but was still difficult to master. Barkan (1939) further modified the operation by performing a posterior sclerotomy and then injecting the anterior chamber with fluid, as well as performing multiple iridectomies. Recently there has been a return of interest in the transcorneal section, which, if performed with the operating microscope, is safe and has many advantages over the traditional subconjunctival approach (Charleux and Etienne, 1974).

Lowe $(1962,1973)$ conclusively showed the value of prophylactic peripheral iridectomy in preventing acute attacks.

The purpose of this study was to elucidate the outcome of peripheral iridectomy performed in all cases in which the intraocular pressure had been controlled medically after an acute attack, and in particular to discover the time of onset, the effect, and the correct management of persistently raised intraocular pressure following the treatment of the acute attack (post-iridectomy glaucoma (Forbes and Becker, 1964)).

\section{Materials and methods}

One hundred and fifty-five eyes of 83 patients (56 females, 27 males) had peripheral iridectomies performed between January 1965 and July 1976 
and were followed up until they died or until December 1976. These patients were from a local, stable, white population and only $3 \%$ were lost to follow-up. The ages of the patients ranged from 44 to 90 years (Table 1).

Eighty-one peripheral iridectomies (Table 2) were performed for primary angle-closure glaucoma (8 of these were in the other eye of patients who had bilateral attacks). One of these peripheral iridectomies had to be repeated because the iridectomy was not full-thickness.

Eleven peripheral iridectomies were performed in patients in whom an acute attack had been precipi-

Table 1 Age of patients with primary angle-closure glaucoma

\begin{tabular}{ll}
\hline $\begin{array}{l}77 \text { patients }(81 \text { eyes }) \\
\text { Age in years }\end{array}$ & Number of patients \\
\hline $41-50$ & 1 \\
$51-60$ & 16 \\
$61-70$ & 22 \\
$71-80$ & 28 \\
$>81$ & 10 \\
\hline
\end{tabular}

Youngest patient, 44 years. Oldest patient, 90 years

Table 2 Therapy for angle-closure glaucoma

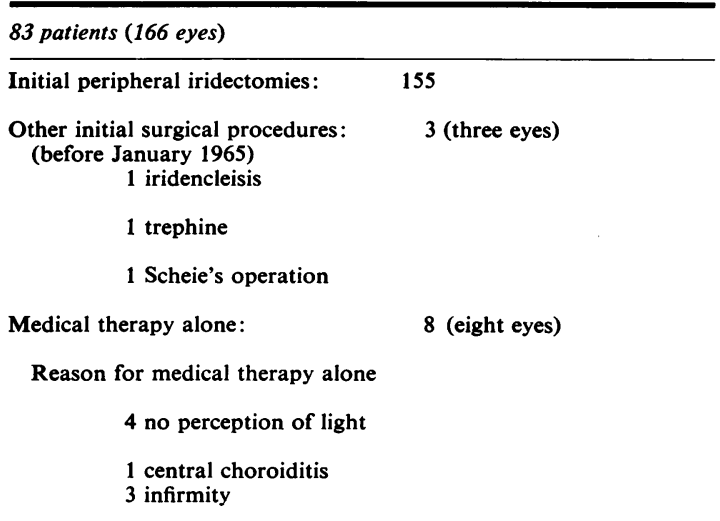

Table 3 Reason for peripheral iridectomy

\begin{tabular}{lr}
\hline $\begin{array}{l}\text { Primary angle-closure glaucoma (includes } 8 \text { bilateral } \\
\text { attacks) }\end{array}$ & 81 eyes* \\
Mydriatic-induced angle-closure glaucoma & 11 eyes \\
Prophylatic peripheral iridectomies & 60 eyes \\
Ocular hypertension (fellow eye) & 3 eyes \\
\hline
\end{tabular}

- All patients with acute angle-closure glaucoma had the intraocular pressure controlled with medical therapy before surgery tated by mydriatics in the outpatient department (Table 3); 63 patients had prophylactic iridectomies, and in 3 of these patients the intraocular pressure was slightly raised at the time of surgery (Table 3 ).

A patient presenting with acute angle-closure glaucoma in our clinic has the history recorded, including the duration of symptoms, especially pain, blurring, and haloes, and the presence of any precipitating factors. The visual acuity is assessed and the intraocular pressure taken. The state of the external eye, cornea, anterior chamber, iris, and lens is noted. Particular attention is paid to the presence of spiralling of the iris and glaukomflecken. If the disc can be seen it is described in detail. An attempt is made to assess the visual field in both eyes, and gonioscopy is performed after instilling glycerin $1 \%$ in the conjunctival sac.

Over the years the initial medical treatment has varied considerably but has always consisted in the frequent instillation of miotics and acetazolamide and the occasional use of osmotic agents. The present routine is to instil pilocarpine $4 \%$ every quarter hour for 2 hours and then 4 times a day; $500 \mathrm{mg}$ of acetazolamide intravenously is given initially, and this is followed by $500 \mathrm{mg}$ orally 3 times a day (a lesser dose is sometimes given). Osmotic agents and sedation are now rarely used. Miotics are no longer instilled in the fellow eye. Peripheral iridectomy is performed under general anaesthetic within a few days but not on the day of admission. A prophylactic peripheral iridectomy is performed as a separate procedure within the week. After operation the acetazolamide is stopped and the pupil dilated with cyclopentolate $1 \%$. Corticosteroid drops are not given as a routine.

The follow-up of these patients is a vital part of their care. They are seen frequently in the glaucoma clinic after operation until the pressures are found to be normal and stable. The visual fields and discs are examined carefully at each visit. If there is any increase in the size of the disc cup or there is a progressive field defect, pilocarpine $4 \%$ is given 3 times a day. If control is still not gained, trabeculectomy is performed. Some patients require further medical or surgical therapy after this.

\section{Results}

Of the 81 eyes with primary angle-closure glaucoma peripheral iridectomy alone completely controlled the glaucoma in 58 eyes $(72 \%)$ as judged by return to normal of the intraocular pressure and by the maintenance of the visual field. Twenty-three patients (28\%) required pilocarpine therapy in addition (Table 4). This was successful in 10 patients $(12 \%)$. Further surgery was required in 13 eyes $(16 \%)$ 
(Table 5). One eye had 2 trabeculectomies before control was achieved; the rest required miotic therapy.

Of those who had further surgery 7 had a pressure of $34 \mathrm{mmHg}$ or more 1 month after the peripheral iridectomy; 4 had pressures of less than $21 \mathrm{mmHg}$ at 1 month but the pressures had risen to between

Table 4 Pilocarpine therapy following peripheral iridectomy

Number of eyes on miotic therapy

(a) after acute primary angle-closure glaucoma 23 eyes

(b) after mydriatic-induced angle-closure glaucoma 6 eyes

(c) after prophylactic iridectomy $\quad 1$ eye

(d) after peripheral iridectomy in fellow eye with ocular hypertension

0 eyes

(e) after subsequent surgical procedure following peripheral iridectomy

3 eyes

$(f)$ as an alternative to surgery

3 eyes

Table 5 Time after peripheral iridectomy of further surgical procedures

\begin{tabular}{cl}
\hline Time after peripheral iridectomy & Control \\
\hline Within 1 month & 1 \\
1 Scheie's operation & 0 \\
1 Trabeculectomy & 1 \\
1 Krasnov operation & \\
Within 4 months & 2 \\
4 Trabeculectomies & 1 \\
1 Trephine & 0 \\
2 Krasnov operations & \\
Between 4 and 6 months & 1 \\
2 Trabeculectomies & 1 \\
1 Anterior sclerotomy & 1 \\
\hline
\end{tabular}

Control is here regarded as tension less than $21 \mathrm{mmHg}$ and stable field without further medication
22 and $50 \mathrm{mmHg}$ by the fourth month. On the other hand 3 patients with tensions of 25 to $30 \mathrm{mmHg}$ 1 month after operation were eventually easily controlled with pilocarpine drops alone, but only 1 patient whose pressure was at this level at 4 months could be similarly controlled. Because of infirmity 3 patients whose pressures were 44,28 , and $27 \mathrm{mmHg}$ respectively 1 month after surgery have been maintained on acetazolamide permanently. In all, 13 patients required pilocarpine therapy after peripheral iridectomy or further surgery in primary acute-angle glaucoma.

Of the 11 peripheral iridectomies performed for mydriatic-induced angle-closure glaucoma 6 were in 3 patients who already had disc and field changes and were previously considered to have chronic simple glaucoma. These patients were already using pilocarpine drops, and this therapy was continued after the iridectomy. Neither medical nor surgical therapy was necessary in the other eyes. One patient with a prophlylactic iridectomy needed pilocarpine therapy to maintain an intraocular pressure of $21 \mathrm{mmHg}$. The 3 eyes with ocular hypertension had their tensions returned to normal by peripheral iridectomy.

The duration of the attack prior to presentation was no indication that the patient would eventually require either miotic therapy or surgery. Five patients with histories of 5 days' duration of symptoms were controlled by peripheral iridectomy alone, yet 3 patients with symptoms of 2 days only needed further surgery (Table 6). Similarly, no correlation could be found between the final result and the height of the intraocular pressure before or after medical therapy (Tables 7 and 8). Again the presence of iris atrophy, spiralling, or glaukomflecken could not be shown to be related to the need for subsequent pilocarpine therapy or surgical procedures (Tables 9 and 10).

Although no correlation could be found between the initial visual acuity and the final result, those eyes which had had an acute attack had worse vision than those which had had peripheral iridec-

Table 6 Duration of symptoms in 65 eyes with primary angle-closure glaucoma and their subsequent glaucoma control

\begin{tabular}{|c|c|c|c|c|c|c|}
\hline \multirow{2}{*}{$\frac{\text { Duration }}{24 \text { hours or less }}$} & \multicolumn{2}{|c|}{$\begin{array}{l}\text { Peripheral iridectomy } \\
\text { Control Non-control }\end{array}$} & \multicolumn{2}{|c|}{$\begin{array}{l}\text { With peripheral iridectomy } \\
\text { and pilocarpine }\end{array}$} & \multicolumn{2}{|c|}{ With further surgery } \\
\hline & 20 & - & 5 & 1 & - & 1 \\
\hline 2 days & 5 & 2 & 1 & - & 3 & - \\
\hline 3 days & 7 & - & 1 & - & - & 1 \\
\hline 4 days & 3 & - & 一 & 1 & - & - \\
\hline 5 days or more & 5 & 1 & 1 & 3 & 2 & 2 \\
\hline Total & 40 & 3 & 8 & 5 & 5 & 4 \\
\hline
\end{tabular}


Table 7 Initial tension in primary angle-closure glaucoma and subsequent control

\begin{tabular}{|c|c|c|c|c|c|c|}
\hline \multirow{2}{*}{$\frac{\text { Tension }(\mathrm{mmHg})}{40-50}$} & \multicolumn{2}{|c|}{$\begin{array}{l}\text { Peripheral iridectomy } \\
\text { Control Non-control }\end{array}$} & \multicolumn{2}{|c|}{$\begin{array}{l}\text { Subsequent pilocarpine } \\
\text { Control Non-control }\end{array}$} & \multicolumn{2}{|c|}{$\begin{array}{l}\text { Further surgery } \\
\text { Control Non-control }\end{array}$} \\
\hline & 14 & 2 & 4 & 1 & 2 & 2 \\
\hline $51-60$ & 15 & 2 & 3 & - & 2 & 1 \\
\hline $61-70$ & 8 & - & 2 & 1 & 3 & 1 \\
\hline $70+$ & 6 & - & - & - & - & - \\
\hline
\end{tabular}

Total of 70 tensions only as 3 unrecorded in hospital and 8 given acetazolamide by general practitioner

Table 8 Preoperative tension after medical therapy and subsequent control

\begin{tabular}{|c|c|c|c|c|c|c|}
\hline Pre-op. tension $(\mathrm{mmHg})$ & $\begin{array}{l}\text { Peripheral ir } \\
\text { Control }\end{array}$ & $\begin{array}{l}\text { ridectomy } \\
\text { Non-control }\end{array}$ & $\begin{array}{l}\text { Subsequent } p \\
\text { Control }\end{array}$ & $\begin{array}{l}\text { pilocarpine } \\
\text { Non-control }\end{array}$ & $\begin{array}{l}\text { Subsequent } \\
\text { Control }\end{array}$ & $\begin{array}{l}\text { further surgery } \\
\text { Non-control }\end{array}$ \\
\hline 10 or less & 15 & - & - & 1 & 1 & - \\
\hline $11-20$ & 20 & - & 9 & - & 4 & 1 \\
\hline $21-30$ & 4 & 2 & - & - & - & 2 \\
\hline $31-40$ & 2 & - & - & - & - & - \\
\hline$>40$ & 3 & - & - & - & 1 & - \\
\hline
\end{tabular}

Total, 64 tensions. No record for 17

Table 9 Presence of iris atrophy and spiralling at time of presentation and subsequent control

14 eyes out of 67 eyes examined showed atrophy or spiralling

6 controlled with peripheral iridectomy alone

4 controlled with pilocarpine subsequently

4 needed further surgery and control still not gained in 3

Table 10 Presence of glaukomflecken at the time of presentation and subsequent control

Glaukomflecken in 4 eyes out of 66 examined

1 controlled by peripheral iridectomy alone

2 controlled with subsequent pilocarpine

1 controlled after further surgical procedure

tomy performed as a prophylactic procedure (Table 11). Of the 68 eyes with a follow-up of at least 5 years 8 had cataract extractions, 1 being in the eye which had had a prophylactic iridectomy.

The probable causes for visual acuity of less than 6/60 at 5 to 11 years were: 3 eyes with acute angle closure of several weeks' duration and untreated, 1 of only 24 hours' duration; 3 cases of uncontrolled residual glaucoma; 2 cases of cataract; 1 case of herpes zoster ophthalmicus; and 1 case of central choroiditis. The damaging effect of post-iridectomy glaucoma was obvious by 4 months in all eyes (Table 12).
Table 11 Visual acuities following primary acute angle-closure glaucoma (after Lowe, 1973). The 34 patients (68 eyes) with 5 to 11 years follow-up

\begin{tabular}{|c|c|c|c|c|}
\hline $\begin{array}{l}\text { Visual } \\
\text { acuity }\end{array}$ & $\begin{array}{l}\text { Affected e } \\
\text { Initial ope } \\
\text { Drainage } \\
\text { procedure }\end{array}$ & $\begin{array}{l}\text { e } \\
\text { Perion } \\
\text { iridectomy }\end{array}$ & $\begin{array}{l}\text { Fellow eye } \\
\text { Initial operation } \\
\text { Peripheral } \\
\text { iridectomy }\end{array}$ & $\begin{array}{l}\text { No } \\
\text { operation }\end{array}$ \\
\hline $6 / 5$ & - & - & 3 & 一 \\
\hline $6 / 6$ & - & 2 & 3 & - \\
\hline $6 / 9$ & - & 3 & 4 & - \\
\hline $6 / 12$ & - & 6 & 5 & - \\
\hline $6 / 18$ & - & 7 & 6 & 2 \\
\hline $6 / 24$ & - & 3 & 3 & - \\
\hline $6 / 36$ & - & 6 & 2 & - \\
\hline $6 / 60$ & - & 1 & 1 & - \\
\hline $3 / 60$ & - & 3 & - & - \\
\hline CF & 2 & - & - & 1 \\
\hline $\mathbf{H M}$ & - & 2 & - & - \\
\hline $\mathbf{P}$ of $\mathbf{L}$ & 一 & - & - & 1 \\
\hline NPL & - & 1 & - & 1 \\
\hline
\end{tabular}

Table 12 Time interval following peripheral iridectomy when disc cupping and glaucomatous field defects were noted (16 eyes)

\begin{tabular}{lr}
\hline By 1 month: & 10 eyes \\
By 4 months: & 6 eyes
\end{tabular}




\section{Discussion}

Ever since von Graefe showed that broad iridectomy abolished an acute attack of angle-closure glaucoma and that useful vision often returned to that eye it has been known that this vision may be lost by chronic residual raised intraocular pressure (residual post-iridectomy glaucoma (Forbes and Becker, 1964)).

This study has confirmed that a peripheral iridectomy should be the initial surgical procedure following the termination of an acute attack with miotics and acetazolamide, $72 \%$ being completely controlled by peripheral iridectomy alone. A further $12 \%$ were controlled simply by the addition of pilocarpine. The problem has been to predict which patients will require this additional therapy or further surgery, which we found to be successful in a further $10 \%$. This leaves $6 \%$ uncontrolled at any one time (Tables 4 and 7).

We have found that it was impossible to predict from preoperative criteria including duration of symptoms (Table 6), initial visual acuity, intraocular tensions before (Table 7) and after (Table 8) medical therapy, presence of spiralling and atrophy of the iris (Table 9), glaukomflecken of the lens (Table 10), and Goldmann gonioscopy preoperatively or at operation which patient would be left with a residual raised pressure and need further medical and/or surgical therapy.

Recognising that post-iridectomy glaucoma may occur, we have devoted much attention to predicting this on preoperative examination. The most reliable routine is to estimate the degree of angle closed by peripheral anterior synechiae, there being a direct relationship between degree of synechial closure and postoperative glaucoma (Chandler, 1952; Forbes, 1974). It is said to be possible to differentiate appositional contact from synechial closure preoperatively by indentation gonioscopy (Forbes, 1966, 1974) or operative gonioscopy (Shaffer, 1957 Unfortunately this correlation is not absolute and is, in our experience, unreliable. Furthermore these examinations cannot detect trabecular damage due to prior iris contact (Barkan, 1954).

The treatment of choice must be peripheral iridectomy with extremely careful and very frequent follow-up to determine those patients in whom the intraocular pressure is going to remain uncontrolled.

To our knowledge, no one has emphasised the remarkable speed with which the field can be lost following peripheral iridectomy after an acute attack, many eyes being severely damaged within 3 months of the acute attack if the residual glaucoma is not controlled. Readings of the early postoperative intraocular pressures alone are not sufficient to predict which eyes will be further damaged. Several patients with only slightly raised intraocular pressures developed severe field loss with extreme rapidity, and it is therefore essential to examine the visual fields and observe the optic discs at not longer than 2-weekly intervals for at least 4 months after surgery (Table 11). It seems that the disc can become excavated extremely rapidly in those patients who have not previously been subjected to prolonged moderate rises of intraocular pressure.

The intraocular pressure usually becomes stable at low levels within 4 months, but by this time the damage has been done.

If there is any evidence of visual field loss, then further surgery, preferably trabeculectomy, should be performed. Miotics alone are usually inadequate, and procrastination is dangerous (Playfair and Watson, 1978). The longer the interval between failure of control and surgery the worse the surgical results. Those eyes operated upon between 4 and 6 months later were left with very little useful field of vision even though the intraocular pressure was controlled (Table 5).

At the beginning of this investigation we were not certain which operative procedure was likely to be the most effective. For example, Scheie reported excellent results for iridectomy with scleral cautery for neglected cases of acute closed-angle glaucoma (Scheie, 1964). We now conclude that trabeculectomy is both safe and usually effective, but the operation may need to be repeated several times on the same eye. The ability to reform the anterior chamber at the end of the operation diminishes the chances of inducing malignant glaucoma. The conclusions reached over the Krasnov operation (Playfair and Watson, 1978) also apply to this group of patients. We do not consider it to have any particular advantage over trabeculectomy. We could not find any evidence that the density of cataracts increased after peripheral iridectomy.

Prophylactic iridectomy was first advocated by von Graefe for subacute attacks (von Graefe, 1857), and its value in asymptomatic fellow eyes has been particularly emphasised by Lowe $(1962,1973)$. We confirm this view. Only 1 of our patients required further miotic therapy after peripheral iridectomy.

We thank all the staff of the Eye Department for their help and co-operation in the collation of this material and in particular Mr J. E. Cairns and Mr J. D. Scott for their permission to include their patients in the survey. We also thank Mrs J. McCombie for typing the manuscript and the Medical Illustration Department for its help with the tables.

\section{References}

Adler, F. H. (1929). Iridectomy in glaucoma (abridged translation of von Graefe's article'. Archives of Ophthal- 
mology. 1, 71-86.

Barkan, O. (1938). Glaucoma: classification, causes and surgical control. Results of microgonioscopic research. American Journal of Ophthalmology, 21, 1099-1117.

Barkan, O. (1939). An operative procedure for glaucoma of shallow chamber type. Multiple excisions of the root of the iris and deepening of the anterior chamber. Archives of Ophthalmology, 21, 331-345.

Barkan, O. (1954). Iridectomy in narrow-angle glaucoma. American Journal of Ophthalmology, 37, 504-519.

Chandler, P. A. (1950). Malignant glaucoma. Transactions of the American Ophthalmological Society, 48, 128-143.

Chandler, P. A. (1952). Narrow-angle glaucoma. Archives of Ophthalmology, 47, 695-716.

Chandler, P. A., and Grant, W. M. (1962). Mydriaticcycloplegic treatment in malignant glaucoma. Archives of Ophthalmology, 68, 353-359.

Charleux, J., and Etienne, R. (1974). Iridectomie basale transcorneene. Technique operatoire. Bulletin des Societies D' Ophthalmologie, 74, 237-241.

Curran, E. J. (1920). A new operation for glaucoma involving a new principle in the aetiology and treatment of chronic primary glaucoma. Archives of Ophthalmology, 49, 131155.

Curran, E. J. (1931). Peripheral iridotomy in acute and chronic glaucoma: some results after ten years' duration. Anatomical classification of glaucoma. Transactions of the Ophthalmological Societies of the United Kingdom, 51, 520-538.
Forbes, M. (1966). Gonioscopy with corneal indentation. A method of distinguishing between apportional closure and synechial closure. Archives of Ophthalmology, 76, 488-492.

Forbes, M. (1974). Indentation gonioscopy and efficiency of iridectomy in angle closure glaucoma. Transactions of the American Ophthalmological Society, 72, 488-515.

Forbes, M., and Becker, B. (1964). Iridectomy in advanced angle-closure glaucoma. American Journal of Ophthalmology, 57, 57-62.

Lowe, R. F. (1962). Acute angle-closure glaucoma. The second eye: an analysis of 200 cases. British Journal of Ophthalmology, 46, 641-650.

Lowe, R. F., (1973). Primary angle-closure glaucoma. A review five years after bilateral surgery. British Journal of Ophthalmology, 57, 457-463.

Playfair, T. J., and Watson, P. G. (1978). The management of chronic or intermittent primary angle-closure glaucoma: a long-term follow-up of the results of peripheral iridectomy used as an initial procedure. British Journal of Ophthalmology, 62, 000-000.

Scheie, H. (1964). Iridectomy with scleral cautery-current status. Transactions of the Ophthalmological Societies of the United Kingdom, 84, 127-137.

Shaffer, R. N. (1957). Operating room gonioscopy in angle closure glaucoma surgery. Transactions of the American Ophthalmological Society, 55, 59-66.

von Graefe, A. (1857). Ueber die iridectomie bei glaucom und über den glaucomatösen process. Archiv für Ophthalmologie, 3, 456-555. 